\title{
Attitudes and support needs of Black Caribbean, south Asian and White British carers of people with dementia in the UK
}

\author{
Vanessa Lawrence, Joanna Murray, Kritika Samsi and Sube Banerjee
}

\section{Background}

Family carers are the most important source of dementia care, especially among ethnic minority populations, who are less likely to access health or social services. The evidence base on the carer experience in these communities is profoundly limited.

\section{Aims}

To explore the caregiving attitudes, experiences and needs of family carers of people with dementia from the three largest ethnic groups in the UK.

\section{Method}

A qualitative study, using a grounded theory approach. Indepth individual interviews were conducted with 32 carers of people with dementia (10 Black Caribbean, 10 south Asian, 12 White British).

\section{Results}

Carers were identified as holding a 'traditional' or 'nontraditional' caregiver ideology, according to whether they conceptualised caregiving as natural, expected and virtuous. This informed feelings of fulfilment, strain, carers' fears and attitudes towards formal services. The majority of the south Asian, half of the Black Caribbean and a minority of the White British participants were found to possess a traditional ideology.

\section{Conclusions}

The findings suggest that specific cultural attitudes towards the caregiving role have important implications for how carers can best be supported.

\section{Declaration of interest}

None.
In the UK, around two-thirds of older people with dementia are supported in the community, and family members are the most important source of dementia care. ${ }^{1}$ This is especially true among ethnic minority populations, who are less likely to access specialist healthcare or social care services. ${ }^{2}$ South Asian and Black Caribbean populations represent the largest ethnic minority groups in the $\mathrm{UK}^{3}$ yet the evidence base on dementia care in these communities is profoundly limited. ${ }^{4}$ Familial attitudes towards caregiving, and the way individuals appraise and adjust to the role, have implications for how they can best be supported. ${ }^{5}$ With demographic ageing in all populations, we need to improve our understanding of the nature and needs of family carers of people with dementia and how these might vary between ethnic groups. Qualitative research presents an effective methodology for the exploration of cultural differences in caregiver attitudes and beliefs. ${ }^{6}$ We therefore report data from a cross-cultural qualitative study of informal carers of people with dementia.

\section{Method}

\section{Data collection}

This study used rigorous qualitative methodology drawing on the grounded theory approach. ${ }^{7}$ In-depth individual interviews explored attitudes, beliefs and feelings of Black Caribbean, south Asian and White British carers of people with dementia. Participants were recruited from four socially and ethnically diverse south London boroughs (Lambeth, Southwark, Lewisham and Croydon); these include deprived inner-city areas and wealthy suburbs. Caregivers were recruited through community mental health teams for older adults, carer services and organisations (e.g. Lambeth Crossroads, Alzheimer's Society Croydon), and community services aimed at serving Black and minority ethnic groups (e.g. Charisma, a Croydon-based project for older adults from ethnic minority groups with mental health problems and dementia). Recruitment continued until theoretical saturation was reached, that is, until no significant new themes were emerging.

\section{Qualitative interviews}

The interview guide was generated from a review of the literature and expert consultation. Initial topics included: the help-seeking pathway, nature of the caregiving role, coping strategies, attitudes towards the future, informal support, service use and evaluation. Questions were open-ended and revised iteratively, allowing further exploration of the issues raised, for example, the theme 'fulfilment' was introduced by participants and subsequently explored. Interviews were conducted in people's homes, unless participants stated a preference to be seen elsewhere. Interviews lasted around $1 \mathrm{~h}$ and were conducted in the participants' preferred language. All were recorded on audiotape and transcribed verbatim. All participants gave permission at the time of interview for their responses to be used in reports and publications.

\section{Data analysis}

Three of the researchers (V.L., J.M., K.S.) read the first five transcripts repeatedly to immerse themselves in the data; they then independently separated the data into meaningful fragments and emerging themes were identified and labelled with descriptive codes. They compared their individual coding frames until a consensus was reached. V.L. then applied the constant comparison method to delineate the similarities and differences between codes; from this, conceptual categories were formed (e.g. 'continuity in relationship/life', 'caregiving rewards', 'level of responsibility'). Data collection and analysis occurred simultaneously and different perspectives were purposefully sought to test and refine the emergent theory: for example, ethnic minority carers born in 
the UK were purposefully recruited on the basis that they may possess less traditional attitudes towards the caregiving role. Throughout the analysis, ideas about themes and their relationships were recorded in theoretical memos ${ }^{8}$ and discussed at regular intervals with the research team.

\section{Results}

Thirty-two carers participated in an interview: 10 were Black Caribbean ( 9 women, 1 man), 10 south Asian (5 women, 5 men) and 12 White British (11 women, 1 man). The sample captured a variety of ages of carers (ranging from 33 to 87 years) and relationships between carer and patients.

It emerged that carers' attitudes towards the caregiving role accounted for much of the variation in the data, including their concerns, hopes, rewards, and attitudes towards informal and formal support systems. Carers fell into one of two groups according to whether they held three core interrelated beliefs: caregiving is natural, expected and virtuous. Consequently, participants were categorised as holding a 'traditional' or 'non-traditional' caregiver ideology. ${ }^{9}$ The online Table DS1 details the sample characteristics of carers possessing predominantly traditional and non-traditional ideologies. Table 1 summarises the defining features of carers with traditional and non-traditional ideologies.

\section{Traditional caregiver ideology: caregiving is natural, expected and virtuous}

Some caregivers with traditional ideologies identified themselves in ways that suggested a natural inclination towards the caregiving role. For example, it emerged that a high proportion of Black Caribbean carers had experience in the nursing profession, and felt that working in a caring capacity formed an intrinsic part of their identity and equipped them to deal with the caregiving role:

'I'm coming from a nursing background and I do . . . I am a caring person, you know, that's what I do 24/7, so perhaps why none of the caring stuff . . . and even if it got to the point, where it probably will, that I have to physically care for my dad, it wouldn't be a problem.' (BCC3, traditional caregiver ideology, daughter)

We found that the majority of south Asian and Black Caribbean carers with traditional caregiver ideologies possessed strong religious values. These shaped the meaning ascribed to caregiving, both in their motivation to care and the way in which they coped. Providing care was consistent with being a 'good' Hindu or Christian and consequently represented the normal and expected thing to do. For some spousal carers across the three ethnic groups who upheld traditional values, making sacrifices for their partner was consistent with how they conceptualised their marital relationship. Caring was viewed as part of the life-long give and take of marriage and was often explained in the context of their marriage vows:

'I'm sorry that he has Alzheimer's but I'm not sorry for myself that, imagine, that I have to take care of him ... no, no, no ... it's what marriage is for. When you take the oath, you must live by it ... you have to love and you have to cherish and you have to care just the same.' (BCC9, traditional caregiver ideology, wife)

Conversely, spouses with non-traditional ideologies often felt that becoming a carer for their partner was acutely at odds with their pre-existing role within the marriage. Spouses and daughters/sons with non-traditional ideologies also felt that caring conflicted with their sense of self:

I'm an independent person, I'm a very independent Black woman and I . . I I want to . . . to stay that way and I'm a bit confused at the moment. I don't know what is best for both of us.' (BCC5, non-traditional caregiver ideology, wife)

Among those caring for a parent, there was cultural variation in the extent to which caregiving was viewed as a natural part of the life course. Daughter and son carers of south Asian origin who held strong traditional caregiving ideologies were most likely to explain it in these terms:

'You know, as Indians, we always look after our parents. Yes, I am the sole carer, I have no brothers and I just ... my father he looked after me when I was young and he has done lots and lots of things for me so it's my turn to look after him.' (SAC5, traditional caregiver ideology, son)

In contrast, many White British and Black Caribbean daughters/ sons seemed to have adopted the caregiving role in an environment where there was little expectation for them to do so. For these carers, and spouses with non-traditional ideologies, caring was discordant with how they had imagined their life to be:

'I just, I feel that I am practically 80 and I feel I want a bit of peace and quiet; I want someone to help and look after me.' (WBC12, non-traditional caregiver ideology, wife)

Carers across the sample expressed concerns about the standard of residential care homes; indeed many non-traditional carers appeared motivated solely by a desire to avoid this eventuality. However, sons and daughters of south Asian and Black Caribbean origin with traditional ideologies viewed caring less as a necessity and more as an opportunity to reciprocate parental support. Their comments suggested a sense of fulfilment in the caregiving role that was absent from the accounts of White British children with non-traditional ideologies. One daughter, born in the Caribbean, reflected on how her attitude towards caregiving differed from that of her British-born siblings:

'It's something I want to do and I'm glad I can do it. It's almost a privilege to do, but then, you know, I . . as I said I grow up in Jamaica and it's probably a cultural thing. Whereas my younger siblings don't quite have the same dedication, they'll do it because it's Dad but it's not their duty . . . you know what I mean it's just a cultural difference.... that's the way the family unit is from where I'm coming from.' (BCC3, traditional caregiver ideology, daughter)

Table 1 Features of carers

Traditional caregiver ideology

Caregiving expected, natural, virtuous

Lives changed, but ongoing

Sustained sense of reciprocity in relationship

Derive rewards from caregiver role

Perception of available informal support

Prioritise person with dementia

Fearful that circumstances might remove caregiving from their control

Perception of available formal support

Limits placed on support

Offer of support valued
Non-traditional caregiver ideology

Caregiving conflicts with expectations, unnatural and lacking in virtue

Life 'on hold'

Absence of rewards from relationship or caregiver role

Informal support unavailable

Caregiving positioned negatively by relatives

Protect non-caregiver roles

Experience role conflict

Fearful about the indefinite nature of caregiving

Too burdened to 'fight' for help

value early information and advice 


\section{Continuity and rewards}

Holding a traditional caregiving ideology was unrelated to the type or extent of difficulties that carers faced, yet it appeared to assist carers in accommodating change and adapting to the new situation. Regarding caregiving as natural, expected and/or virtuous helped to minimise the disruption felt by carers, and engender a sense of continuity. This enabled carers to continue to derive rewards from the relationship, and to feel that their lives, although changed, were ongoing. This contrasts sharply with those with non-traditional ideologies, for whom caregiving often signified the cessation of their relationship and to a large extent, their lives.

A small number of Black Caribbean and White British carers with traditional ideologies described an enduring closeness in their relationship with the care recipient. Viewing caregiving in the context of the give and take of a long marriage also helped carers with traditional ideologies to relinquish expectations of reciprocity. Several spouses suggested that this was a joint commitment and that their partner would have made similar sacrifices had the situation been reversed. The view that caregiving was an opportunity to reciprocate past love and support was most pronounced among south Asian and Black Caribbean sons/ daughters with traditional ideologies. The belief that caring was a natural development in life assisted them in adapting to the profound change in roles, while enabling their relationship with the person with dementia to continue. Conversely, spouses and sons/daughters with non-traditional ideologies were more likely to feel that the changes in their loved-one constituted the end of their relationship. White British offspring were among the most likely to feel that the relationship that they had known and valued had been lost:

'In a way she's not my Mum any more, that's the hard bit, she's just sometimes. she can be a difficult old lady that you have to keep your eye on.' (WBC10, nontraditional caregiver ideology, daughter)

Many of these participants felt obliged to provide care because of the responsibility inherent in the relationship; they no longer derived rewards from the relationship itself and the sense that they 'had to' rather than 'wanted to' assume caregiving typified their remarks:

'I have to do it because there is no one else to do it so I just get on with it. It's my wife, it is my lawful wife, so what can I do? The only thing I could do is run off and leave he in the house on her own and that wouldn't be right.' (BCC4, non-traditional caregiver ideology, husband)

In these instances, there was a sense of unreciprocated love and support. Carers were unable to make sense of the situation in terms of the give and take of marriage and often lacked the conviction that their spouse would have done the same for them:

'If the boot were on the other foot he wouldn't look after me. I know that for a fact because I had cancer and he was good before I had the operation: once I had had it he didn't want to talk about it, he didn't want to know, that was it, finished.' (WBC12, non-traditional caregiver ideology, wife)

Not all carers had previously benefited from a close or intimate relationship with the person with dementia, and two traditional south Asian children hoped to strengthen their bond with their parent. Becoming a carer represented a good model of behaviour, which permitted them to assume the role of a good son or daughter in their parent's life. This was consistent with religious beliefs held by a large number of Black and minority ethnic carers, which located caregiving as virtuous behaviour that may subsequently be rewarded. Traditional carers were more likely to feel they had chosen the caregiving role, which perpetuated its perceived desirability. Nine carers with a non-traditional ideology explicitly stated that they felt their lives had temporarily stopped, and they looked forward to completing their obligation. Therefore, only after relinquishing the caregiving role might opportunities for fulfilment arise. However, this notion provided little consolation during the ongoing challenge of caregiving:

'I don't . . . wouldn't call it rewarding, in any shape or form; maybe if you're caring for somebody who's gonna get better. Or if you're caring for somebody who's gonna die in 6 months time, but if you're caring for somebody who's gonna go on, like my mother for 12 years, then I . . . I wouldn't find anything rewarding or anything to do with it.' (WBC5, non-traditional caregiver ideology, daughter)

The caregiving role threatened to obscure many meaningful aspects of carers' lives, yet provided those with non-traditional ideologies with few new rewards. Invariably, these carers described feeling burdened, stressed, isolated, and trapped. Understandably, some expressed a strong desire to escape from the caregiving role: 'You know, sometimes I feel like driving away and not coming back you know. You know, just drive, could be anywhere. You do understand how people could just drive away, because often you hear of people who just disappear and you realise they are not killing themselves, they are just disappearing to start a new life.' (BCC7, nontraditional caregiver ideology, daughter)

\section{Informal support}

\section{Sole responsibility}

Carers' ideologies seemed to influence, as well as to be shaped by, their perception of informal support. Seventeen carers identified themselves as the sole providers of care and 12 of these held a non-traditional ideology. Among the non-traditional group, many close family members had distanced themselves from the situation or refused direct requests for help. There was a strong sense that these carers had adopted the role out of necessity, and they lacked the belief that support was available if needed:

'I do have a brother, but as soon as my mother got ill, he just evaporated as if never saw him again ... even when I was looking after Mum at home, I'd say to my brother, "look, would you mind going round there one Sunday a month, so at least I can go out with my family", I could have one day where I could, but [he said], "I like to be spontaneous, I don't like to plan ahead". So that was that.' (WBC5, non-traditional caregiver ideology, daughter)

Families of non-traditional carers not only avoided providing support but also provoked feelings of guilt and uncertainty in the primary caregiver. Carers often felt under enormous pressure from the wider family to place the person with dementia in a residential home. The perceived attitude and behaviour of these family members positioned caregiving as an unnatural and unnecessary task lacking in virtue. Carers often felt isolated by their decision to provide care, having internalised the belief that it was their cross to bear:

'I don't like to bug people, like my brother says, "it's your problem, you took it on".' (BCC7, non-traditional caregiver ideology, daughter)

\section{Assisted responsibility}

Among the seven carers in this group, six were spouses and all held a traditional ideology. These carers also identified themselves as the principal caregiver for the person with dementia, yet this presented as a role that they had adopted willingly. Friends and family had made offers of help, and carers were confident that support existed should the need arise:

'Well, my daughter works with it, she gets all this all the time, so she knew basically, but she said, "if something can be done we will do it together Mum" so she's always available anyway if I wanted help.' (WBC4, traditional caregiver ideology, wife)

However, it was clear that these carers also placed limits on the help that they asked for and accepted. They preferred not to inconvenience people, but also appeared keen to preserve the independence of the care recipient, and their relationship, for as long as possible.

\section{Shared responsibility}

Five children and two friends described themselves as sharing the caregiving responsibility with other members of the care 
recipients' family. Each occupied a clear role according to their relationship with the person with dementia and their individual circumstances. These carers, and family members, mostly held strong traditional caregiver ideologies:

'Well, I just sit beside her when nobody is there and at night I sleep in the room here but apart from that my sisters come in the morning to see that she is washed properly and given breakfast properly, and they give the meal in the day time, and so on. (SAC4, traditional caregiver ideology, son)

\section{Nature of the caregiving role}

Integration with other roles

Many of the strains among carers with non-traditional ideologies arose from endeavouring to fulfil caregiving obligations alongside other occupational and family commitments. Carers with both traditional and non-traditional ideologies experienced financial difficulties and demands associated with raising a family. However, traditional carers emerged as more likely to sacrifice non-caregiving roles where possible, e.g. working, socialising. Conversely, non-traditional carers attached greater importance to protecting these aspects of their life, which they felt constituted a definitive part of their identity. The lack of time spent with friends or enjoying hobbies seemed to symbolise the way in which the care recipients' interests had superseded their own. Many younger carers with non-traditional ideologies worried that they were neglecting their families, and their spouses were more likely to represent a source of concern rather than of support. Carers made extraordinary efforts to maintain a multiplicity of roles, but inevitably the needs of some went unmet:

'Do you put your parents first, your children first, your husband first or what you know? You try to give them all little bits of time. My husband was actually lying in bed last night and I was sort of asleep, and I heard him moan and he said to me "you know, you are never around, you are never there for me anymore" and I thought bloody hell, you know, I'm sleeping, I ignored him I was so exhausted.' (SAC8, nontraditional caregiving ideology, daughter)

Caregiving had a negative impact on health across the sample. Many felt that they were constantly battling exhaustion; they were often deprived of sleep and the constant demands of caregiving afforded few opportunities to recharge.

\section{Willingness to prioritise care recipient}

Three carers with a traditional ideology associated good caregiving with a willingness to sacrifice their own needs in favour of the care recipients'. Prioritising the person with dementia was viewed as virtuous behaviour:

I'm there for her at any time at any, you know, which is really important, it's not that you're coming in and out, and the time she needs someone, there won't be anyone there, so I think I'm doing an excellent job for her . . . some people would like to be independent to do some. try to do some things but you never know what they can do that will hurt them, really, so I think that when you are there throughout, it really helps.' (BCC2, traditional caregiver ideology, daughter)

One White British daughter with a non-traditional ideology berated herself for resenting the caregiver role, and identified a good carer as one that does not experience conflict:

'I still feel that I'm doing it because I've got to do it not because I sort of actually wan to. There's ... there's a difference between thinking, "oh I'll go and see Mum tonight" rather than, "I've got to go and see Mum tonight", you know, that sort of thing. A good carer is somebody that whizzes in and does things willingly and doesn't care. (WBC10, non-traditional caregiving ideology, daughter)

\section{Attitude towards the future}

The majority of carers expressed fears about the future, which appeared to reveal their underlying attitudes towards care. A number of non-traditional carers worried about the indefinite nature of the role, but were sustained by the thought of life after caregiving:
Interviewer: What helps you to cope with all of it?

Carer: Just the thought that one day it's going to come to an end. (WBC1, nontraditional caregiver ideology, son)

In contrast, the primary fear of many of those with a traditional ideology was that circumstances might remove caregiving from their control. This was most common in elderly spouses who were conscious of the fragility of their own health. Very few carers, regardless of ideology, had taken practical steps to plan for the future. The constant and unpredictable nature of caregiving often demanded that they attend to the immediate challenges. Traditional carers stated that their intention was to provide care for as long as it was needed. Carers with a non-traditional ideology expressed more hesitant attitudes, yet the difficulties that they were coping with suggested that their threshold for abandoning caregiving was extremely high.

\section{Formal support}

\section{Health, social and voluntary services}

Caregivers evaluated health, social and voluntary services on the basis of four criteria: whether they served an emotional or practical function for the person with dementia, and whether they served an emotional or practical function for themselves. These criteria were rarely uniformly met, and carers were often forced to weigh up their loved-one's needs and wants against their own.

\section{Satisfaction with services}

A defining characteristic of carers with a traditional ideology was that they were more likely to feel satisfied with the input of formal services. There was wide variation within the traditional group in terms of the amount and type of services accessed, yet there was a common belief that support was available should they need it.

'They are very helpful, very helpful, in fact I am the one that is not pushing, you understand, because if I go and say, "I need so and so ... " because take for instance, he pee... well, the toilet is down here and we are upstairs and of course he can't go down, and sometimes he wet the carpet because I say to him, "lift the pail" and sometimes he doesn't lift the pail so the carpet, ... a and I asked them to give me a commode and it's here. You know, no problem at all, I just told the nurse and she said, "Ok you need it". Whatever you need is there.' (BCC9, traditional caregiving ideology, wife)

A combination of factors appeared to underlie this general perception of support. First, a common feature among carers with traditional ideologies was the sense that they placed limits on the level of support that they asked for and received. On one level this was evident across the sample, as carers balanced the advantages of services against the disadvantages, such as the disruption of domiciliary support or the unsettling effect of respite care. However, carers with traditional ideologies appeared to attach greater importance to maintaining independence and control over the caregiving situation. Conversely, some carers with nontraditional ideologies appeared eager to relinquish caregiving responsibility, were more demanding of services and more likely to feel that their needs were not being met.

A small number of south Asian carers construed help-seeking as a failure to fulfil their personal responsibility. Circumstances within one family reached crisis point before the care recipient's son felt justified in seeking help. Subsequently, his attitude towards services shifted:

'I think because we didn't know what was available to us we couldn't use the resources to the best. For ourselves. And in taking care of ourselves, that's the best way of caring for my mother. And that's what I realise now.' (SAC1, traditional caregiving ideology, son)

Unfortunately, carers across the sample occasionally likened accessing services to a battle in which they were constantly fighting to receive information, advice and practical assistance. Nontraditional carers were more likely to feel overwhelmed by the caregiving role and described lacking the necessary resources to 
pursue the help they need. All carers wanted help that listened and responded to their individual needs. Non-traditional carers emphasised the importance of the early provision of information in particular. They reflected that they had been bewildered about the availability of services and how they could be accessed. These elements of good care all shared a sense of collaboration, which served to reassure carers that they were not alone.

\section{Discussion}

\section{Cultural attitudes and beliefs surrounding the caregiving role}

Caring for a person with dementia exerts huge psychological, physical and emotional demands on all. However, there is evidence that the experience may differ between ethnic groups. African-American caregivers have been found to report less stress, burden and depression than White caregivers ${ }^{10}$ and to derive more benefit and meaning from the caregiver experience. ${ }^{11}$ Lawton $^{9}$ argued that the relationship between ethnicity and caregiver strain/gain among Black caregivers was mediated by a traditional caregiving ideology, which was defined as a wish to repay the care receiver for previous actions, to continue family traditions, fulfil personal values, and set a good example to children. Subsequent researchers have suggested that African-American caregivers are more likely to view caregiving as a culturally normative process, ${ }^{12}$ have a stronger preference for family care ${ }^{13}$ and a stronger cultural justification for caregiving. ${ }^{14}$ However, other researchers have rejected this hypothesis as a cultural myth, which conveniently mitigates the responsibility of service providers ${ }^{15}$ and limits offers of formal support. ${ }^{16}$

This is the first study to identify patterns of cultural attitudes towards the caregiving role in dementia across the three largest ethnic groups in the UK. We found that identifying caregiving as natural, expected and virtuous did not negate the need for formal services, ${ }^{17}$ but did have important implications for how carers could best be supported (Table 2). We have adopted Lawton's ${ }^{9}$ typology as it is compatible with these cultural beliefs and enables us to avoid adding unnecessarily to the existing body of concept labels. This cluster of attitudes is typically associated with minority ethnic populations, yet we found that the majority of south Asian, half the black Caribbean and a minority of White British participants held a traditional ideology. This suggests some acculturation of belief ${ }^{18}$ and that a strong emphasis on kinship ties and familial responsibilities is not specific to minority groups. ${ }^{19}$

\section{Supporting carers with a traditional caregiver ideology}

Identifying caregiving as a natural role appeared to assist carers in accommodating change, and helped sustain continuity in their relationship with the person with dementia and their lives as a whole. This is consistent with reports that ethnic minority carers often draw upon their biographical narratives, which positions caregiving as a 'virtuous' state, to make sense of their situation. ${ }^{20}$ Carers who retained continuity in their relationship adopted various strategies to maintain a sense of reciprocity with the person with dementia.

Many carers with traditional ideologies implicitly prioritised the care recipients' needs over their own physical and mental health, and made decisions regarding service use on this basis. This may explain the association between strong cultural justifications for caregiving and poor evaluations of physical health among African-American caregivers. ${ }^{21}$ Services that are perceived as benefiting the person with dementia (e.g. day centres were repeatedly identified) offer an important solution. However, professional care staff must also reassure carers that it is both natural and necessary to take time for themselves. Staff should stress that services that allow carers to recuperate their emotional and physical strength ultimately benefit the person with dementia. $^{22}$

It is also important to note that some south Asian carers with traditional ideologies identified asking for professional help as a failure to fulfil their responsibilities. Services might be considered more acceptable if they could communicate their commitment to respecting individual preferences for care, and to supporting, rather than substituting, family members in the caregiving role.

There was a propensity across the sample for carers to avoid addressing concerns about the future. Open discussion and planning for the future might alleviate concerns among traditional carers, who feared their own health might deteriorate, thus removing caregiving from their control. Critically, it would also reassure them that support would be available should they require it in the future. The perceived availability of support provided enormous comfort in this group, regardless of whether they wished to access it at that time.

Table 2 Support given for traditional and non-traditional caregivers

\begin{tabular}{|c|c|c|}
\hline & Theme & Service response \\
\hline \multirow{4}{*}{$\begin{array}{l}\text { Traditional } \\
\text { caregiver } \\
\text { ideology }\end{array}$} & $\begin{array}{l}\text { Implicitly prioritise person with dementia's needs. } \\
\text { Make decisions regarding service use on this basis }\end{array}$ & $\begin{array}{l}\text { Promote services that are perceived to benefit the person with dementia, } \\
\text { e.g. day care. Reassurance that time for themselves is necessary }\end{array}$ \\
\hline & $\begin{array}{l}\text { Place limits on support, but still need to know that it is } \\
\text { available }\end{array}$ & $\begin{array}{l}\text { Care professionals need to understand that offers of assistance are of } \\
\text { great value }\end{array}$ \\
\hline & $\begin{array}{l}\text { Seeking professional help a failure to fulfil caregiving } \\
\text { responsibility }\end{array}$ & $\begin{array}{l}\text { Public education - service providers committed to supporting, rather than } \\
\text { substituting, family members in the caregiving role }\end{array}$ \\
\hline & Fearful about the future & $\begin{array}{l}\text { Planning and open discussion. Reassurance that support is available should } \\
\text { they need it }\end{array}$ \\
\hline \multirow{5}{*}{$\begin{array}{l}\text { Non-traditional } \\
\text { caregiver } \\
\text { ideology }\end{array}$} & Known rewards of relationship lost & $\begin{array}{l}\text { Interventions that help carers to reframe their relationship, and to identify } \\
\text { enduring or new elements that they value within it }\end{array}$ \\
\hline & Lack of rewards from the caregiver role & $\begin{array}{l}\text { Recognise and promote the value of the caregiving role. Acknowledge and } \\
\text { address the feelings of the wider family }\end{array}$ \\
\hline & Derive important rewards from non-caregiver roles & Support carers in maintaining non-caregiver roles \\
\hline & Experience role conflict & $\begin{array}{l}\text { Modify appraisal of success: conflict in demands does not mean they are } \\
\text { a 'bad carer' }\end{array}$ \\
\hline & $\begin{array}{l}\text { Few opportunities to evaluate how they feel about } \\
\text { the caregiving role }\end{array}$ & Regular reviews enable them to assess how they feel \\
\hline
\end{tabular}




\section{Supporting carers with a non-traditional caregiving ideology}

In contrast to traditional carers, those with non-traditional ideologies were more likely to feel that an imbalance existed in their relationship, as the rewards that they had previously known and valued had been lost. These carers may therefore benefit from interventions that help to reframe their relationship, and to identify enduring or new elements that they value within it. Carers with non-traditional ideologies were also less likely to derive rewards from the caregiving role itself, as they often lacked the conviction that it represented virtuous behaviour. Health and social care providers are in a position to recognise and promote the value of the care that loved-ones provide. A growing focus on the positive aspects of caregiving has underlined the importance of enhancing caregiver rewards as well ameliorating caregiver strains. ${ }^{23}$ It is also useful to note that it may be insufficient for care professionals to work with the primary caregiver alone, given that the findings suggest that siblings, spouses and children are pivotal in informing carers' attitudes towards the role. Thus, it would be beneficial to adopt a systemic approach that acknowledges the feelings of the wider family. ${ }^{24}$

This absence of intrinsic rewards may explain why individuals with non-traditional ideologies appeared to attach greater importance to remaining in their jobs and protecting their social lives. These roles provided fulfilment, yet also led to role conflict, as previously demonstrated within non-traditional carers. ${ }^{13}$ It is important that service providers appreciate the benefits of maintaining non-caregiver roles, ${ }^{25}$ and offer as much practical support as possible. It may also be necessary to modify the way carers appraise their success: they should not expect to perform multiple roles faultlessly, and need to understand that they can still be a 'good carer' even if they experience conflict in the needs of those around them.

Few non-traditional carers had identified a threshold for relinquishing the role and many persevered despite feeling increasingly overwhelmed. Formal mechanisms such as regular reviews might provide these carers with an opportunity to evaluate how they feel about the current situation. There is scope for a change in governmental policy and the benefits system to directly support and promote the role of family carers. This could include explicitly acknowledging the value that those individuals bring to society in terms of preventing expensive institutionalisation. Specific grants or targeted benefits would help to legitimise the caregiving role as well as directly help those who care. Our data support the absolute need for caregivers to be supported and the need for that support to be tailored to the needs of the carer. The insights provided by this qualitative research can help the formulation of systematic strategies to support carers, whose effectiveness can be tested by quantitative research such as randomised controlled trials

\section{Limitations}

It is important to acknowledge that there is considerable heterogeneity within the south Asian and Black Caribbean populations. However, there is a paucity of evidence in this area, and we felt that it was important to compare and contrast beliefs across groups, rather than focusing on a single highly defined population. Although the study took place in south London, participants were recruited from areas in which a range of socio-economic diversity exists. Most elders from minority ethnic groups in the UK live in urban areas such as these. However, the applicability of this typology should be tested in these and other ethnic groups throughout the UK. We also recognise the predominance of female carers within our sample, and regret that we have been unable to explore how gender relates to caregiver ideology. Further research might also consider the relevance of this typology to carers for other patient groups.

Vanessa Lawrence, BSC, Joanna Murray, BA, Kritika Samsi MA, and Sube Banerjee, MB BS, MD, MSC, FRCPsych, Section of Mental Health and Ageing, Health Service and Population Research Department, Institute of Psychiatry, King's College London, UK

Correspondence: Professor Sube Banerjee, Institute of Psychiatry, London SE5 8AF, UK. Email: s.banerjee@iop.kcl.ac.uk

First received 17 Sep 2007, final revision 12 Feb 2008, accepted 5 Mar 2008

\section{Acknowledgements}

We express our gratitude to all of the carers who took part in this research and who kindly gave us their time and thoughts. We also thank the care professionals within the community mental health teams and voluntary organisations that helped us to identify suitable participants. We are very grateful to Professors Dinesh Bhugra, Peter Huxley, André Tylee and Alastair Macdonald for their advice and insights in the conduct of this work. This study was funded by a grant from the UK Department of Health's Policy Research Programme. The opinions expressed are those of the authors.

\section{References}

1 National Audit Office. Improving Services and Support for People with Dementia. The Stationery Office (TSO), 2007.

2 Social Services Inspectorate. Improving Older People's Services: Policy into Practice. Inspection of Social Care Services for Older People. Department of Health, 2001

3 Briggs K, Ashkam J. The Needs of People with Dementia and Those Who Care for Them: A Review of the Literature. Alzheimer's Society, 1999.

4 Milne A, Chryssanthopoulou C. Dementia care-giving in Black and Asian populations: reviewing and refining the research agenda. J Community Appl Soc Psychol 2005; 15: 319-37.

5 Murray J, Livingston G. A qualitative study of adjustment to caring for an older spouse with psychiatric illness. Ageing Soc 1998; 18: 659-71.

6 Dilworth-Anderson P, Gibson BE. The cultural influence of values, norms, meanings and perceptions in understanding dementia in ethnic minorities. Alzheimer Dis Assoc Disord 2002; 16 (suppl 2): s56-63.

7 Glaser BG, Strauss AL. The Discovery of Grounded Theory: Strategies for Qualitative Research. Aldine, 1967.

8 Glaser B. Emergence v. Forcing: Basics of Grounded Theory Analysis Sociology Press, 1992.

9 Lawton MP, Rajagopal D, Brody E, Kleban MH. The dynamics of caregiving for a demented elder among black and white families. J Gerontol B Psychol Sci SOC Sci 1992; 27: s156-64.

10 Connell CM, Gibson GD. Racial, ethnic, and cultural differences in dementia caregiving: review and analysis. Gerontologist 1997; 37: 355-64.

11 Haley WE, Gitlin LN, Wisniewski SR, Mahoney DF, Coon DW, Winter L, Corcoran M, Schinfeld S, Ory M. Well-being, appraisal and coping in AfricanAmerican and Caucasian dementia caregivers: findings from the REACH study. Aging Ment Health 2004; 8: 316-29.

12 Haley WE, Roth DL, Coleton MI, Ford GR, West CAC, Collins RP, Isobe TL. Appraisal, coping and social support as mediators of well-being in Black and White caregivers of patients with Alzheimer's disease. J Consult Clin Psychol 1996; 64: 120-9.

13 Long Foley K, Tung HJ, Mutran EJ. Self-gain and self-loss among African American and White caregivers. J Gerontol B Psychol Sci Soc Sci 2002; 57 s14-22.

14 Dilworth-Anderson $\mathrm{P}$, Brummett $\mathrm{BH}$, Goodwin $\mathrm{P}$, Wallace Williams $\mathrm{S}$, Williams RB, Siegler IC. Effect of race for cultural justifications for caregiving J Gerontol B Psychol Sci Soc Sci 2005; 60: s257-62.

15 Atkin K, Rollings J. Informal care in Asian and Afro-Caribbean communities: a literature review. Br J Soc Work 1992; 22: 405-18.

16 Fox K, Hinton WL, Levkoff S. Take up the caregiver's burden: stories of care for urban African American elders with dementia. Cult Med Psychiatry 1999; 23: $501-29$.

17 Boneham MA, Williams KE. Elderly people from ethnic minorities in Liverpool: mental illness, unmet need and barriers to service use. Health Soc Care Community 1997; 5: 173-80.

18 Burton LM, Sorensen S. Temporal context and the caregiving role: perspectives from ethnographic studies of multigenerational African- 
American families. In Caregiving Systems: Formal and Informal Helpers (eds SH Zarit, LI Pearlin, KW Schaie): 47-66. Lawrence Erlbaum Associates,1993.

19 Pyke KD, Bengston VL. Caring more or less: individualistic and collectivist systems of family eldercare. J Marriage Fam 1996; 58: 379-92.

20 Adamson J, Donovan JL. 'Normal disruption': South Asian and African/ Caribbean relatives caring for an older family member in the UK. Soc Sci Med 2005; 60: 37-48.

21 Dilworth-Anderson P, Goodwin P, Wallace Williams S. Can culture help explain the physical health effects of caregiving over time among African American caregivers? J Gerontol B Psychol Sci Soc Sci 2004; 59: 138-45.

22 Gallagher-Thompson D. The family as the unit of assessment and treatment in work with ethnically diverse older adults with dementia. In Ethnicity and the Dementias (2nd edn) (eds G Yeo, D Gallagher-Thompson): 119-124. Routledge, 2006.

23 Kramer B, J. Gain in the caregiving experience: where are we? What next? Gerontologist 1997; 37: 218-32.

24 Dilworth-Anderson $\mathrm{P}$, Gibson BE, Burke JD. Working with African American families. In Ethnicity and the Dementias (2nd edn) (eds G Yeo, D GallagherThompson): 125-44. Routledge, 2006.

25 Dautzenberg MGH, Diederiks JPM, Philipsen H, Tan FES. Multigenerational caregiving and well-being: distress of middle-aged daughters providing assistance to elderly parents. Women Health 1999; 29: 57-74.

\section{Recidivism regarded from the Environmental and Psycho-Pathological Standpoints}

\section{Sutherland, J. F. (1908) Journal of Mental Science, 54, 288-290}

There is little use in going back a century to Lord Hales' test of responsibility, viz., that in order to exempt from punishment there must be total deprivation of understanding and memory. It is discredited by jurists as well as alienists. Lord Mansfield's attitude to the test in 1812 is a decided advance on Hales' in so far that to be answerable the accused must possess a mind capable of distinguishing right from wrong generally, and not in relation to the particular act. But in 1843 the point was again raised in an acute form, and the House of Lords propounded certain questions to the judges with reference to the law of insanity with the view to an authoritative exposition which would in future guide courts of justice. These answers, constituting the law of England upon the point, were to the effect that to establish a defence on the ground of insanity it must be provide that at the time of committing the act the accused was labouring under such a defect of reason of the mind as not to know the nature and quality of the act he was doing, or, if he did know it, that he did not know he was doing what was wrong. The question of right and wrong in the abstract is here abandoned. It was to be put, not only in reference to the particular act charged, but also at the time of committing it. Some jurists, and most alienists, are dissatisfied with the insanity test as it stands, but, whatever individual views may be of the criminal law in relation to responsibility thus laid down, it must be apparent to the most ordinary observer that by the acceptance of the authorised test itself, the intoxicated authors of crime, especially homicides, manslaughter, serious assaults, and these form 80 per cent. of such crimes - implying violence and recklessness, would not be held responsible - there is no gainsaying that - and would either be dealt with as insane or punished by long confinement in prison; in either case society would be protected against such potentially dangerous elements in its midst.

Researched by Henry Rollin, Emeritus Consultant Psychiatrist, Horton Hospital, Epsom, Surrey. 